\title{
Quaternary Glaciations in Central China
}

$\mathrm{D}^{\mathrm{R}}$ R. J. S. LEE, the well-known Chinese geologist, has sent to the Editor of NATURE the proofs of a monograph entitled "Quaternary Glaciations in the Lushan Area, Central China" with a series of photographs, intended in the first place for publication in vol. 2, ser. B, of Academia Sinica. Its transfer to England by air transport, with the request that it be placed in the safe custody of a responsible geological institution, conjures up a lively sense of the present and future state of affairs in China; which aspect, however, has no part in this article except in its bearing on the future publication of the monograph. Another aspect, and one having some significance, is that one would scarcely expect Dr. Lee to take such care to ensure the preservation of this material and to have it brought to the critical notice of expert glacialists, if he were not confident of the prime importance of his latest investigations in the Lushan mountain massif.

A few words of explanation are perhaps necessary to a proper understanding of the latter remarks. The very existence of evidences of glaciation in Central China has in the past been questioned by many geologists with experience of glaciated districts. When Dr. Lee in 1934 published his first account of the 'Boulder Clays', striated rocks, transported blocks, etc., in the Lower Yangtze Valley, and invoked true glaciation (as against solifluxion and allied phenomena) to explain the facts, his evidence was challenged by G. L. Barbour after a cursory joint traverse of the ground.

Barbour, while admitting the extraordinary character of many of the deposits, sought to identify them with long periods of abnormal subærial weathering and erosion, possibly commencing so far back as early Pliocene or even Miocene times. The clay matrix of the 'Boulder Clay' was likened to non-glacial loam; the presence of boulders he explained as due to sinking into the leached soil of laterized surface rocks followed by gradual descent to lower ground under gravity; while a theoretical series of structural events was postulated to account for the presence of transported blocks in elevated positions relative to their apparent source. Further, an absence of (1) glacial sculpture, (2) glacio-fluviatile deposits, and (3) roches moutonnées was claimed by Barbour, though it was admitted that shortage of time prevented his seeing many crucial features.

At that time (1934), Barbour was clearly inclined to the belief that the glacial explanation of the Lushan phenomena was not acceptable. Yet he paid high compliment to Lee for "his penetrating recognition of the possible significance of this extraordinary geological occurrence", admitting further that the last word on the matter had not yet been said and that his (Lee's) interpretation had not been disproved.

That Dr. Lee was not deterred by these criticisms from a geologist of wide experience is shown by his energetic pursuit of confirmatory evidence, and the monograph under consideration directs attention to this glacial evidence under the headings (a) geomorphological indications; (b) moraines and their associated deposits; (c) striated rocks. A short account of the bed-rocks of the Lushan is given to enforce the arguments dealing with transported blocks ; and more ambitious inferences than previously attempted are introduced to demonstrate a three-fold glaciation of the Yangtze valley.

A well-contoured map of the Lushan, bounded on the north by the Yangtze River and on the east by the Poyang Lake, accompanies the monograph. It shows the geographical extent of the glaciations and includes the observed indications of fluvio-glacial deposits, terminal and lateral moraines, drainage channels, glacial striæ, and striated boulders. The scale of the map is $1: 50,000$.

A critical review of the monograph is thought to be undesirable here. For it is clear that, failing an intimate knowledge of the area, an unquestioning acceptance of the validity of the glacial terminology must precede any attempt to estimate the full value of the evidence. This assumption is supported by the fact that G. L. Barbour, well experienced in low-latitude glacial phenomena, was unable to put forward final and convincing conclusions regarding the Lushan deposits and allied features. Attention will therefore be confined to a summary of the chief points of interest raised by Dr. Lee. Glacial geologists, by permission of the Editor of NATURE in arrangement with the Director of the Geological Survey and Museum, will be afforded the opportunity of consulting the monograph and map at the Survey Library, where the documents are being housed pending further instructions from Dr. Lee.

In his analysis of the glacial evidence, Dr. Lee stresses the fact that landforms have suffered extensive erosion and consequent modification since the last glacial period. The geomorphological indications are therefore not in themselves conclusive; but they were sufficient to inspire Lee and induce him to search for other signs of glacial 


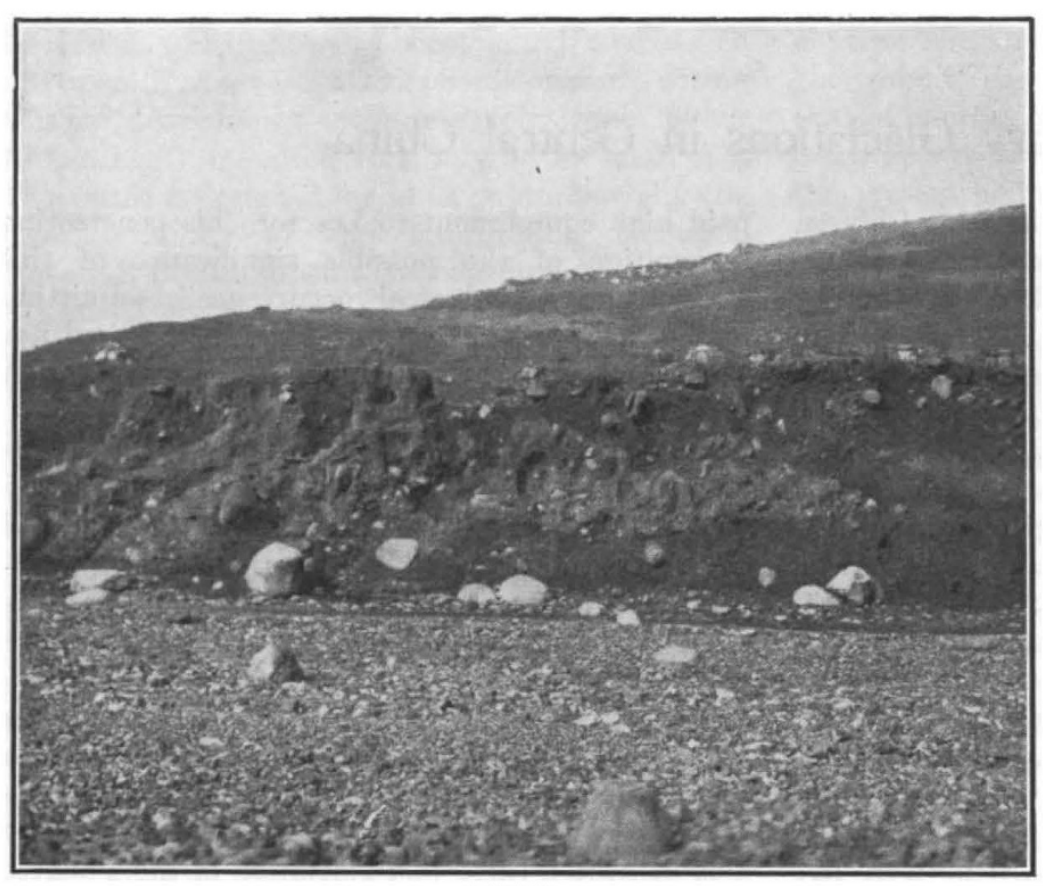

Fig. 1.

A IFNTICULAR MASS OF HARDENED AND LATERIZED BOULDER CLAY OF THE Poyang PERIOD INVOLVED IN THE LOOSER BOULdFR CLAT OF ThE TAKU PERIOD, NEAR THE KUTANG village. but along the side of it." The ravine begins abruptly in front of a mass of Boulder Clay "which proved to be the remnant of an end moraine", and here is a slight similarity to certain drift-diverted streams and gorges in Lancashire. Another case of drainage which suggests the former existence of a valley glacier is described from the Chilichung Valley.

In connexion with several dry gaps which have been cut into the north-western ridge of sandstone in the Lushan, the statement that "the only feasible explanation of the origin of these gaps seems to be that they were produced by spills from the glacier" is supported by acceptable evidence. Examples are also given, though with varying assurance, of firn basins, corries, and kindred features; more confidence is expressed in the

phenenoma. The frequent occurrence of rock basins on the top and flank of the northern part of the Lushan is noted, but not accepted indiscriminately as evidence of glacial sculpture. A strong case, however, is made for a true cirque on the central heights at a spot where a circular depression is carved out of resistant rock of uniform composition, free from structural weakness. It has a fairly steep back-wall and hangs to a main valley in front; further examples on the southeastern flank are also described.

A circumstantial account is given of the most striking example of a U-shaped valley seen in the area, namely, the Wangchiapo Valley. One feature is worthy of Lee's own words: "The question therefore arises as to whether the U-shape of the valley is not entirely due to the synclinal structure with the non-resistant Kuniuling rocks being more or less completely removed by stream erosion. That this is not entirely true is indicated by the behaviour of the existing streams and by the deposition of terminal moraines which still survive. . . Here it suffices to note the occurrence of a deep ravine through which the stream pours down the valley. This feature has been incised by the stream and has attained a depth of no less than $70 \mathrm{~m}$. below the floor of the valley at Wangchiapo.

Beds of the Wulafoeng Grit are thereby excavated in the form of a trench ; and curiously enough, the trench does not run along the axis of the syncline or the lowest part of the valley bottom

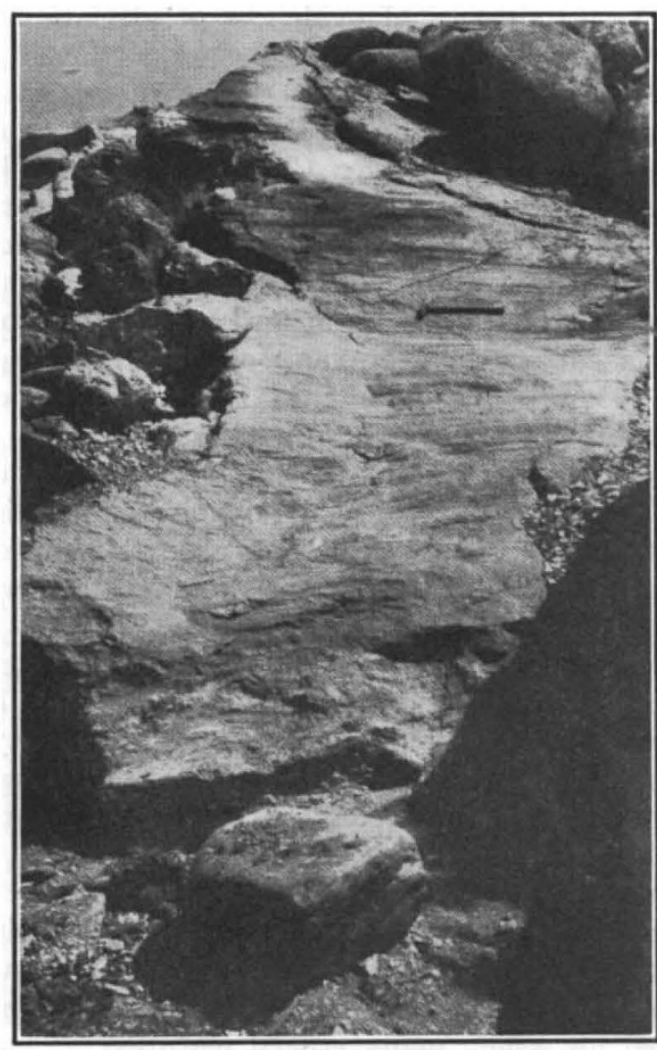

Fig. 2.

Glactal pavement near Patshitsui, striat point. ING SOUTH-EAST; BEDDING PLANE DIPPING NORTHWEST AT ABOUT $20^{\circ}$. 
case of two "zungenbecken" or "central basins" relics of piedmont glaciers on the north side of the mountain.

Coming now to the important matter of depositional evidence, that is, moraines, boulderclay, etc., we are presented with an interesting story leading to the postulation of three glaciations, associated with three distinct types of boulder-clay. The two lowland types are illustrated in Fig. 1, which shows the incorporation of blocks of the earlier well consolidated dark red variety by the later brick-red less consolidated one. The latter is more widespread and has undergone less laterization. It is important to note, in view of Barbour's earlier objection that the boulders in the boulder-clay were invariably hard quartzites and grit, that Lee now emphasizes their lithological variety. Lateral and terminal moraines, a block moraine, and an outwash apron are instanced, though a fuller development of these is said to be lacking as a result of excessive, interand post-glacial destruction. Solifluxion has been found inadequate to explain the transfer of large blocks over the long distances required; the famous Poyang Lake section of glacial drift containing such boulders is $9 \mathrm{~km}$. from their source in the Lushan, and the intervening pre-glacial gradient is negligible, yet is, according to Lee, demonstrably greater than in Boulder Clay times.

Finally, the scratched boulders and striated rock surfaces (Fig. 2) are claimed by Lee to be perhaps the most convincing evidence for glacial operation, and it need only be remarked that Barbour's scepticism on this matter must have created in Lee a strong urge to test this type of evidence very thoroughly.

W. L.

\section{Obituary Notices}

\section{Dr. G. E. Hale, For.Mem.R.S.}

$\mathrm{B}$ $Y$ the death of George Ellery Hale on February 22, at Pasadena, California, solar physics loses its greatest leader. Born in Chicago on June 29, 1868, he had already in 1890 , before completing his studies at the Massachusetts Institute of Technology, begun working at the Harvard College Observatory on his idea of a spectroheliograph. Resisting the temptation to accept Prof. Holden's offer of opportunities to develop his new instrument in connexon with the 36-in. refractor at the Lick Observatory, he established with his father's help a private observatory at Kenwood, in a suburb of Chicago. There, working in the fourth order of a 4-in. Rowland grating attached to a 12.2-in. equatorial, he studied the spectrum of the solar prominences and photographed them in monochromatic light, using first of all the bright $K$ line of calcium. As he found by photographic spectroscopic observations that the bright $K_{2}$ line could be detected here and there on the disk of the sun, he extended his work to monochromatic studies of the whole solar disk, finding the presence of great areas of glowing calcium clouds in general around sunspots. By 1892, his pioneer work had won for him recognition by the University of Chicago, of which he became an associate professor.

Through the munificence of C. T. Yerkes, by no means the last wealthy man in whom Hale was to inspire confidence in his ability to make excellent use of large benefactions, he was given charge of the new Yerkes Observatory at Williams Bay, Wisconsin, with the largest refractor in the world $(40$-in.) and with the Rumford spectroheliograph, which gave him an image of the sun 6.5 inches in diameter. At the Yerkes Observatory with Barnard, Burnham and Frost to help him he worked steadily for nearly ten years on stellar spectra and solar problems. The next great instrumental development became possible for him in 1904, through the generous assistance of the Carnegie Institution, when he was made director of the Mount Wilson Observatory. Here he successfully developed the tower telescope $(60 \mathrm{ft}$. and later $150 \mathrm{ft}$.) with underground spectrographs (30 ft. and. $75 \mathrm{ft}$.) for solar work; for high dispersion stellar spectra and work on distant nebulæ the 60-in. and 100-in. reflectors were available, the latter being due to the munificence of J. D. Hooker. He gathered a great team of colleagues together, and the publication of the annual report of the Observatory became one of the major events of the astronomical year. Hale's own contributions were mainly on the solar side and included such outstanding discoveries as that of the intense magnetic fields in single sunspots, the existence of bipolarity in groups of spots of opposite polarity, the change of polarity of such bipolar spots after each sunspot minimum and the relatively weak general magnetic field of the sun (a full account of Hale's solar work is given in an article by Prof. H. F. Newall in the series of Scientific Worthies in Nature of July 1, 1933, p. 1).

In 1923, under the strain of his many activities, Dr. Hale's health gave way and he retired from the active directorship of the Observatory to become honorary director. But his work was not done. On the observational side, he developed the spectrohelioscope, now a valuable instrument in the study of solar eruptions of short duration and of their reaction on the terrestrial ionosphere; on the administrative side he was mainly responsible for securing in 1928 the grant from the Education Branch of the Rockefeller Foundation, which made it possible to undertake the heavy task of constructing a reflecting telescope with a mirror $200 \mathrm{in}$. in diameter. Hale took a large share in the preliminary 